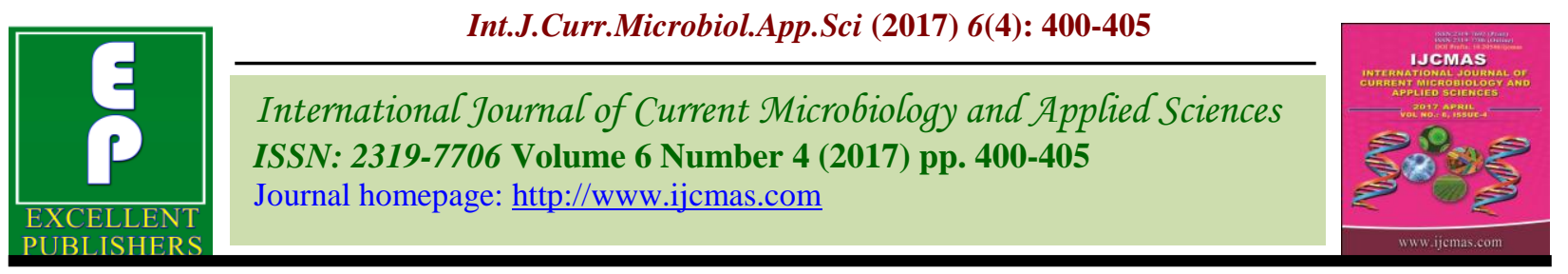

Original Research Article

https://doi.org/10.20546/ijcmas.2017.604.045

\title{
Sensitivity Comparison of Immuno-Histochemical and Histopathological Approaches for Diagnosis of Rabies in Animals
}

\author{
Ajaz Ahmad $^{1 *}$ and C.K. Singh ${ }^{2}$ \\ ${ }^{1}$ Department of Veterinary Pathology, College of Veterinary Science, Guru Angad Dev \\ Veterinary and Animal Sciences University, Ludhiana 141004, Punjab, India \\ ${ }^{2}$ Animal Disease Research Centre, Guru Angad Dev Veterinary and Animal Sciences University, \\ Ludhiana 141004, Punjab, India \\ *Corresponding author
}

\section{A B S T R A C T}

Keywords

Fluorescent antibody test, Histopathology, Immuno histochemistry, Rabies.

Article Info

Accepted: 02 March 2017 Available Online: 10 April 2017
To study the approach of immunohistochemistry (IHC) in comparison with study of pathomorphological alterations, for diagnosis of rabies, 50 brain samples from different animals like dog, cattle, buffalo and mongoose suspected for rabies were collected at post mortem hall. Out of the 50 animal brain samples tested, $30(60 \%)$ were confirmed to be rabid by Fluorescent Antibody Technique (FAT). The 30 positive brain samples were subjected for comparison of histopathology and immunohistochemistry. Sensitivity of diagnosis of rabies by histopathology and IHC was $88.23 \%$ and $93.75 \%$ respectively. The specificity of diagnosis of rabies by histopathology and IHC was $100 \%$ each whereas the accuracy of diagnosis of rabies by histopathology and IHC was $92.59 \%$ and $96.15 \%$ respectively. The immunohistochemistry is more sensitive than histopathology for diagnosis of rabies in formalin fixed brain samples. It is, therefore, recommended to supplement histopathology with IHC as an alternative diagnostic technique especially in the laboratories that resort to histopathology for diagnosis of rabies, in absence of facilities for immunofluorescence.

\section{Introduction}

Rabies is a zoonotic disease caused by highly neurotropic Lyssa virus. Every year approximately 55,000 people die all over the world because of rabies (WHO, 2005;Sudarshan,2004) of which more than 35,000 die from Asia and about 25,000 from India alone (Warrell and Warrell, 1995).

FAT is a gold standard and validated diagnostic test that confirm the presence of rabies virus in brain tissue. However, sophisticated laboratory infra-structure and highly trained personnel are required for conducting rabies diagnosis by immunofluorescence. On the other hand, immunohistochemistry (IHC), with its immunological approach of antigen detection is expected to be close to FAT in sensitivity of detection of rabies in brain tissues. IHC is also feasible on formalin fixed histological sections in most of the laboratories where routine histopathological approach is feasible. IHC is expected to detect rabies antigen that is not discernible with histopathological examination. Thus, the present study was envisaged to elucidate the feasibility of IHC 
for use as an alternate approach for confirmation of rabies in the laboratories where facilities for immunofluorescence do not exist.

\section{Materials and Methods}

Fifty brain samples were collected from 27 dogs, 11cattle, 9 buffalos and 3 mongooses between Jan 2014 to Jan 2015. The samples were obtained from post-mortem hall, Department of Veterinary Pathology, GDVASU Ludhiana, Punjab and some samples collected directly from the field where rabies cases had been reported. For Fluorescent Antibody Test suspected brain samples were stored at $-20{ }^{\circ} \mathrm{C}$. For Histopathology and IHC brain tissues samples were fixed and stored in $10 \%$ neutral buffered formalin.

\section{Fluorescent antibody test (FAT)}

FAT was carried out on fresh brain sample following the standard protocol (Meslin, 1996). Glass slides with impression smears of brain tissue were placed in coplin jar containing acetone and fixed at $-4^{\circ} \mathrm{C}$ for 1 hour. Control positive slides from known rabies positive case and control negative slide from normal, uninfected animal were also included in the test. The slides were air-dried and incubated with lyophilized anti-rabies nucleocapsid conjugate (Bio-Rad, France) for $35 \mathrm{~min}$ at $37^{\circ} \mathrm{C}$ in a humid chamber and washed with Phosphate Buffered Saline (PBS) in 3 successive washes for 5-10 minutes. The slides were rinsed with distilled water and air-dried. The cover slip was mounted by adding buffered glycerol on the smear. The slides were visualized under an immuno-fluorescent microscope (Zeiss). Bright apple-green, round to oval bodies were observed. Positive and negative controls were run together with the test specimens.

\section{Histopathology}

Brian tissues samples including cerebellum, cerebrum and hippocampus were collected in $10 \%$ neutral buffered formalin solution from animals suspected for rabies. After fixation in $10 \%$ neutral buffered formalin, tissue samples were given overnight washings under tap water. Then, dehydration of samples was done through ascending grades of alcohol (70\%, 80\%, 90\%, and absolute alcohol) followed by clearing with acetone. Tissues were embedded in paraffin wax (Leica Microsystem) for further processing and 4-5 $\mu$ thick sections were cut. The paraffin sections were stained with routine Hematoxylin and Eosin technique (Luna, 1968). Slides were examined by BX61 Research Photomicrograph Microscope System (Olympus Corporation, USA).

\section{Immunohistochemistry}

Anti rabbit polyclonal antisera raised in Rabies Research-cum-Diagnostic Laboratory of the department was used as primary antibody in IHC. Advanced SS ${ }^{\mathrm{TM}}$ One step polymer Horseradish Peroxidase (HRPO) Immunohistochemical detection system (BioGenex Laboratories Inc., San Ramon, California, USA) counterstained with Gill's haematoxylin was used. IHC was done as recommended by the manufacturer with some modifications. Formalin fixed brain samples were thoroughly washed in running water; dehydrated in ascending grades of alcohol and acetone; cleared in benzene and embedded in paraffin at $58^{\circ} \mathrm{C}$ (Pedroso et al., 2008). The paraffin embedded tissues were sectioned at $5 \mu \mathrm{m}$ thickness and sister sections were taken on Superfrost/Plus, positively charged, microscopic slides (Fisher Scientific, USA) for each sample. Then, the sections were deparaffinized and rehydrated by immersing in $250 \mathrm{ml} \mathrm{EZ-AR} \mathrm{common} \mathrm{solution} \mathrm{at} 70^{\circ} \mathrm{C}$ for 10 minutes in EZ-Retriever $\mathrm{R}$ System 
V.2.1 and subsequent antigen retrieval was done in Citrate buffer (0.01 M, pH 6.0-6.2) at $95^{\circ} \mathrm{C}$ for 10 minutes and at $98^{\circ} \mathrm{C}$ for 5 minutes in EZ-Retriever R System V.2.1. Then three washing were given in PBS buffer for 3 minutes each. The endogenous tissue peroxidases were inactivated by immersion of slides in $3 \%$ hydrogen peroxide solution in methanol for 15 minutes at room temperature in humid chamber followed by three washings with PBS buffer for 3 minutes each.

Non-specific binding was blocked by incubating sections with ready to use power block for 10 minutes at room temperature in moist chamber. On one section of each slide, primary polyclonal rabbit anti-rabies antibody 1:1000 dilution in PBS was added for 1 hour in moist chamber at room temperature.

On the second section of each slide, PBS was added and no primary antibody was added so as to serve as a negative control. The sections were given three washing in PBS buffer for 3 minutes each, thereafter, incubated with polymer HRP (Super Sensitive label, One Step Polymer-HRPO Reagent) for 30 minutes at room temperature in moist chamber followed by three washing in PBS buffer for 3 minutes each.

The antigen antibody- peroxidase reaction was developed with a freshly prepared 3,3diaminobenzidine (DAB) solution by mixing 2 drops of DAB chromogen with $1 \mathrm{ml}$ of DAB buffer supplied by the manufacturer adding $5 \mathrm{ml}$ hydrogen peroxide. Sections were washed in distilled water for 5 minutes and counterstained with Gill's haematoxylin (Merck, Germany) for 30 seconds and washed in running tap water for 5 minutes.

Finally, the slides were dehydrated in ascending grades of alcohol, cleared in xylene, mounted in DPX and examined under advanced microscope (BX 61, Olympus
Corporation, USA) available in the department.

Calculation of sensitivity, specificity and accuracy

Sensitivity was calculated as $[\mathrm{TP} /(\mathrm{TP}+\mathrm{FN})] \times$ 100. Specificity was calculated as $[\mathrm{TN} /(\mathrm{TN}+\mathrm{FP})] \times 100$. Accuracy was calculated as $[\mathrm{TP}+\mathrm{TN} /(\mathrm{TP}+\mathrm{FP}+\mathrm{FN}+\mathrm{TN})] \times$ 100 wherein TP was true-positives; FN was false-negatives; TN was true-negatives and FP was false positives as determined by the reference assay i.e. FAT.

\section{Results and Discussion}

Out of fifty brain samples examined, 35 brain samples revealed gross alterations (Figure 1) suggestive of rabies (Table 1). 30 animals $(60 \%)$ were found to be true positive for rabies by direct Fluorescent Antibody technique (Figure 2).

IHC using Polyclonal antiserum detected rabies in brain tissues of 28 cases $(93.33 \%)$ out of 30 cases with sensitivity of $93.75 \%$, specificity of $100 \%$ and accuracy of $96.15 \%$ (Table 1). However, based on histopathological alterations, rabies was confirmed in $24(80 \%)$ cases with $83.33 \%$ sensitivity, $100 \%$ specificity and $89.28 \%$ accuracy.

Negri bodies are pathognomonic for rabies. On histopathological examination, Negri bodies were observed as round or oval inclusions within the cytoplasm of nerve cells of animals infected with rabies (Figure 3). Negri bodies were most consistently found in hippocampus, followed by cerebellum and cerebrum of buffaloes and cattle. Higher incidence of Negri bodies was detected in bovines than in dogs as reported by earlier workers (Archana, 2001; Arslan et al., 2004; Jamadagni et al., 2007). 
Table.1 Sensitivity, specificity and Accuracy of H\&E and IHC relative to the FAT for detecting rabies virus in the field brain samples

\begin{tabular}{|c|c|c|c|c|c|c|}
\hline & \multicolumn{2}{|c|}{$\mathrm{H} \& \mathrm{E}$} & \multicolumn{2}{|c|}{ IHC } & \multirow[b]{2}{*}{ Total } \\
\hline & & Positive & Negative & Positive & Negative & \\
\hline \multirow{3}{*}{ FAT } & Positive & 24 & 06 & 28 & 02 & 30 \\
\hline & Negative & 00 & 20 & 00 & 20 & 20 \\
\hline & Total & 24 & 26 & 28 & 22 & 50 \\
\hline \multicolumn{2}{|c|}{ Sensitivity } & \multicolumn{2}{|c|}{$83.33 \%$} & \multicolumn{2}{|c|}{$93.75 \%$} & \\
\hline \multicolumn{2}{|c|}{ Specificity } & \multicolumn{2}{|c|}{$100.00 \%$} & \multicolumn{2}{|c|}{$100.00 \%$} & \\
\hline \multicolumn{2}{|c|}{ Accuracy } & \multicolumn{2}{|c|}{$89.28 \%$} & \multicolumn{2}{|c|}{$96.15 \%$} & \\
\hline
\end{tabular}

Fig.1 Congestion and edema in brain of rabid animal

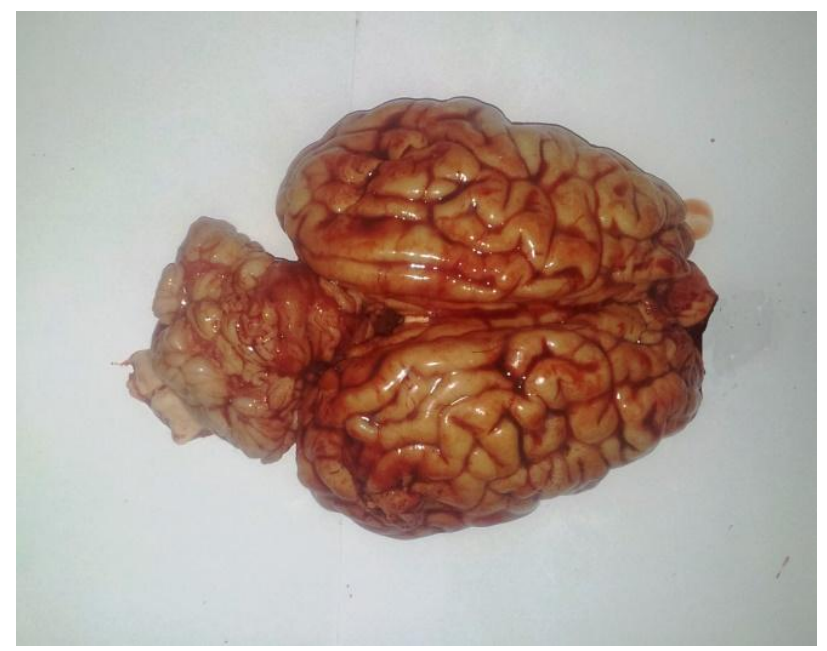

Fig.2 Nervous tissue impression smear showing diffused apple green fluorescence.

Direct FAT x100

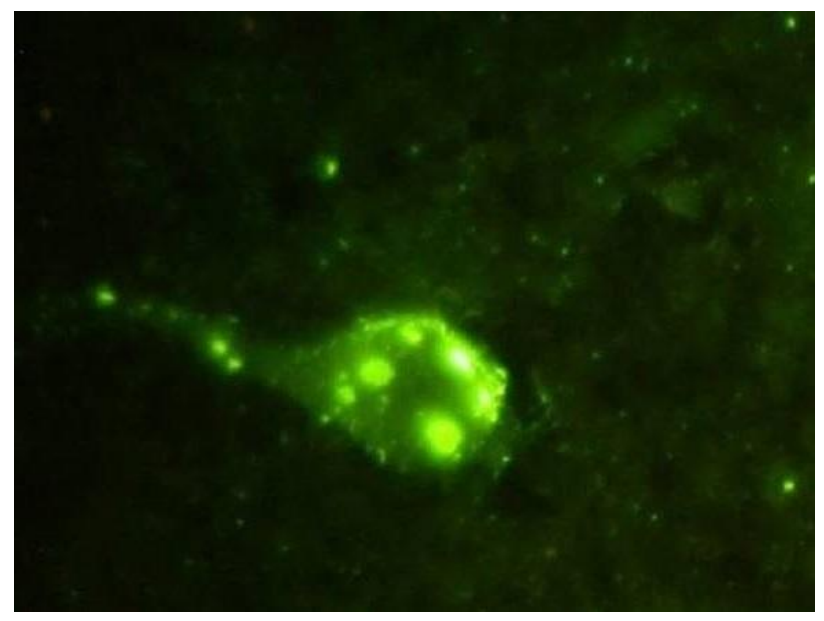


Fig.3 Section of cerebellum showing Negri bodies in the neurons (arrows) H\&E x100

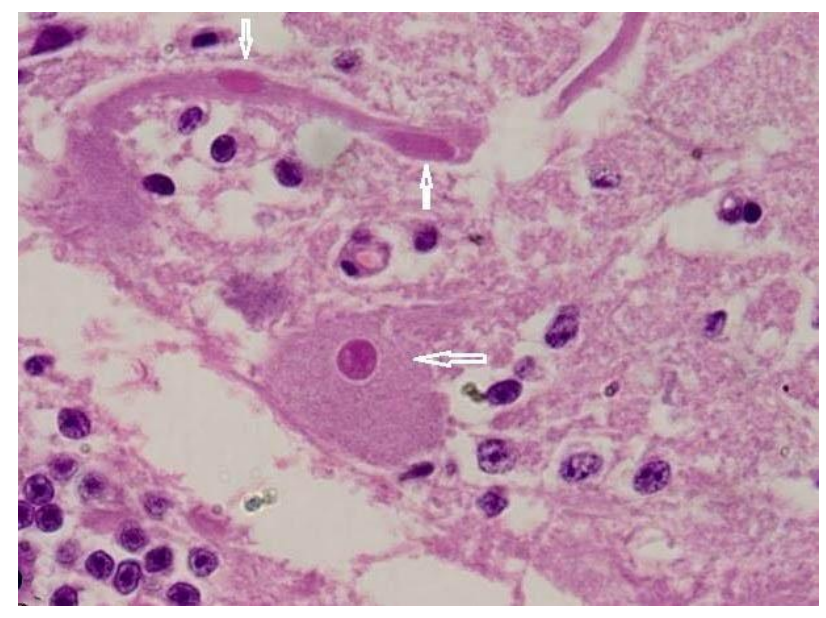

Fig.4 Brain stem of rabid dog showing brown colored Negri bodies and ribonucleoprotein particles in the neurons (arrows) IHC x100

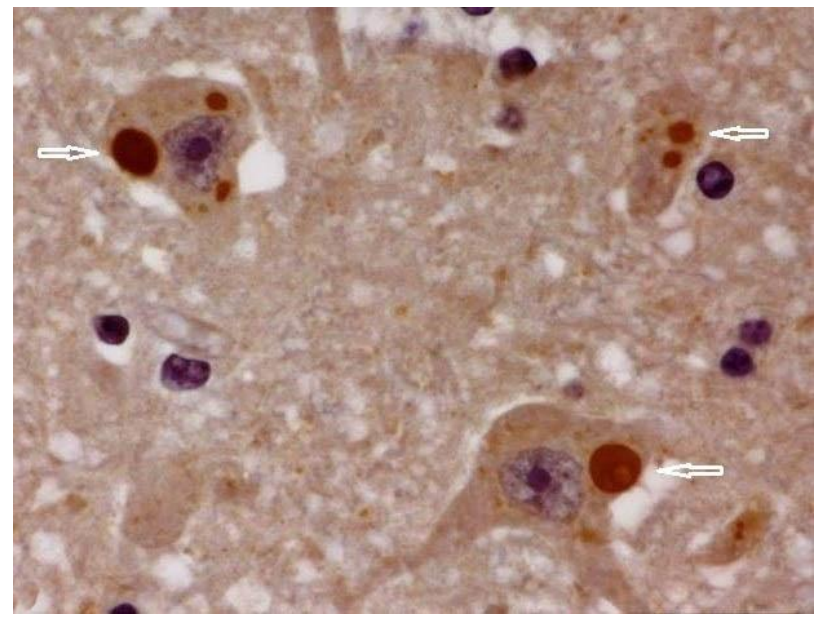

With IHC, distinct, granular rabies viral antigen deposits stained as sharply demarcated brown precipitates of variable sizes were found within the Purkinje cells and in the neurons, axons and in stroma (Figure 4). Polyclonal antibodies employed in detection of rabies antigen in formalin fixed paraffin embedded tissue sections using IHC revealed to be highly efficacious.

IHC could detect rabies antigen that was not clearly visible with $\mathrm{H}$ and $\mathrm{E}$ staining as observed by other workers (Last et al., 1994; Gunawardena and Blakemore, 2007; Rissi et al., 2008). IHC is as sensitive as FAT and is a significant approach for confirmatory rabies diagnosis and can serve as an alternative of FAT where fluorescent microscopy and /or fresh samples are not available for examination by FAT. IHC is effective for formalin-fixed tissue sections, thus, is of immense value for retrospective studies.

\section{Acknowledgement}

The authors are thankful to the Director of Research, Guru Angad Dev Veterinary and Animal Sciences University, Ludhiana for 
providing the necessary facilities and fund for this study.

\section{References}

Archana. 2001. Laboratory diagnosis of rabies by ELISA in buffalo calves experimentally infected with rabies virus. M.V.Sc. Thesis. Punjab Agricultural University, Ludhiana, India.

Arslan, A., Saglam, Y.S., Temur, A. 2004. Detection of rabies viral antigens in non-autolysed and autolysed tissues by using an immunoperoxidase technique. Vet. Rec., 155: 550-552.

Gunawardena, G.S.P., Blakemore, W.F. 2007. Proceedings of the Peradeniya University Research Sessions, Sri Lanka. 12: 168.

Jamadagni, S.B., Singh, C.K., Sandhu, B.S. 2007. Histopathological alterations in brains of rabid infected buffaloes and cattle. Ital. J. Anim. Sci.,6: 872-874.

Last, R.D., Jardine, J.E., Smit, M.M.E., Van Der Lugt, J.J. 1994. Application of immunoperoxidase techniques to formalin-fixed brain tissue for the diagnosis of rabies in southern Africa. Onderstepoort J. Vet. Res., 61: 183-187.

Luna, L.G. 1968. Manual of histologic staining methods of the armed forces institute of pathology, 3rd edn. New York: McGrawHill.

Meslin, F.X., Kaplan, M.M., Koprowski, H. 1996. Laboratory diagnosis of rabies. Geneva. WHO 88-95.

Pedroso, P.M.O., Pescador, C.A., Bandarra, P.M., Raymundo, D.L., Borba, M.R., Wouters, F., Bezerra-Junior, P.S., Driemeier, D. 2008.Standardization of immunohistochemistry technique for detection of rabies virus in formalinfixed and paraffin-embedded tissue samples from central nervous system of cattle. Pesquisa. Vet. Brasil, 28: 627.

Rissi, D.R., Fighera, R.A., Irigoyen, L.F., Kommers, G.D., Claudio, S.L.B. 2008. Occurrence of rabies in sheep in Rio Grande doSul, Brazil. Pesquisa. Vet. Brasil, 28: 495.

Sudarshan, M.K. 2004. Assessing burden of rabies in India. WHO sponsored national multi-centric rabies survey. Assoc. Prev. Control Rabies India, 6: 44-45.

Warrell, D.A., Warrell, M.J. 1995.A continuing challenge in the tropical world. Schweiz Med. Wochenschr., 125: 879-885.

World Health Organization. 2005. WHO Expert Consultation On Rabies, 1st report. Geneva. 1-88.

\section{How to cite this article:}

Ajaz Ahmad and Singh, C.K. 2017. Sensitivity comparison of immuno-histochemical and histopathological approaches for diagnosis of Rabies in animals. Int.J.Curr.Microbiol.App.Sci. 6(4): 400-405. doi: https://doi.org/10.20546/ijcmas.2017.604.045 